Provided for non-commercial research and education use. Not for reproduction, distribution or commercial use.

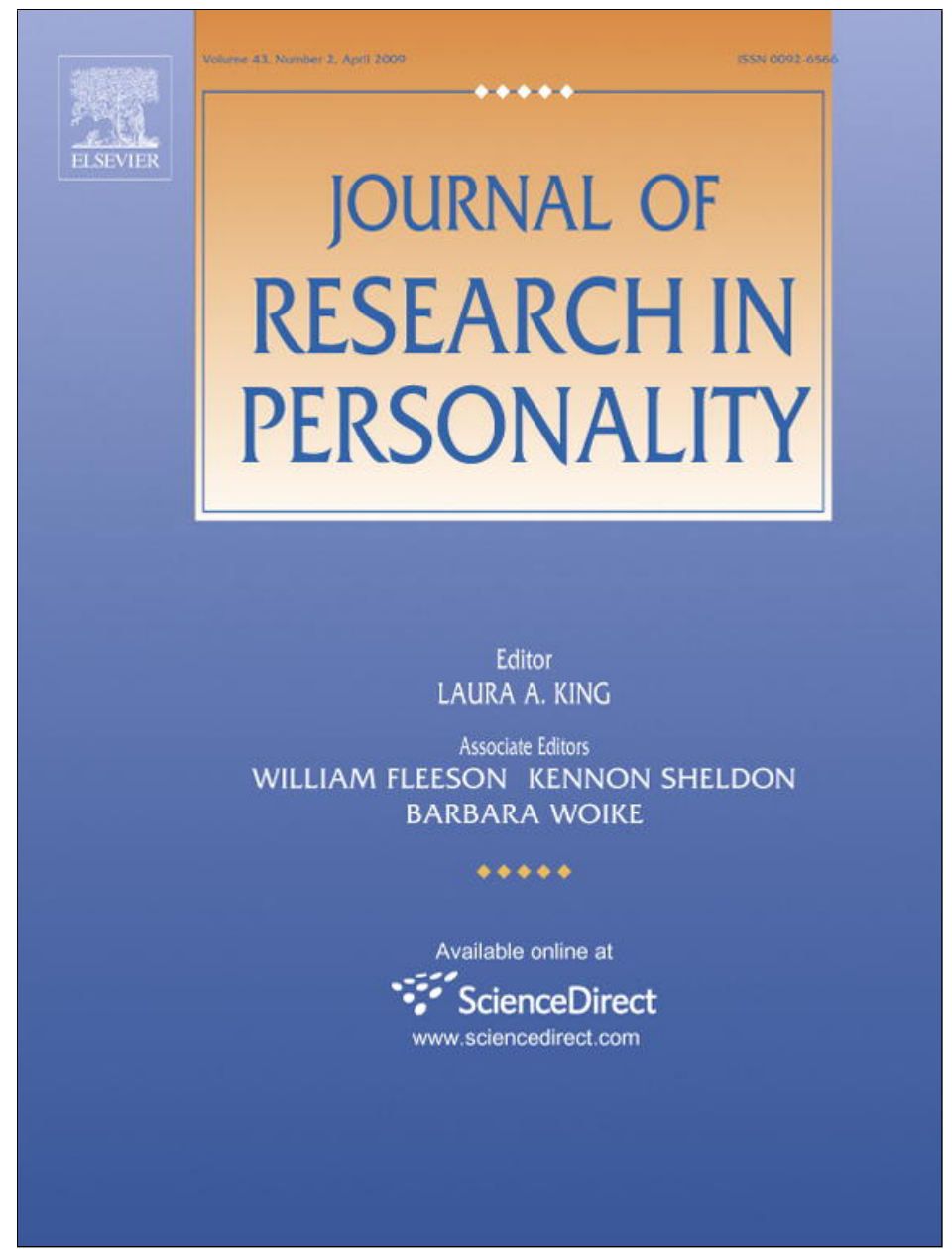

This article appeared in a journal published by Elsevier. The attached copy is furnished to the author for internal non-commercial research and education use, including for instruction at the authors institution and sharing with colleagues.

Other uses, including reproduction and distribution, or selling or licensing copies, or posting to personal, institutional or third party websites are prohibited.

In most cases authors are permitted to post their version of the article (e.g. in Word or Tex form) to their personal website or institutional repository. Authors requiring further information regarding Elsevier's archiving and manuscript policies are encouraged to visit:

http://www.elsevier.com/copyright 


\title{
Three decades after the personality paradox: Understanding situations
}

\author{
Vivian Zayas $^{\mathrm{a}, *}$, Yuichi Shoda ${ }^{\mathrm{b}}$ \\ ${ }^{a}$ Department of Psychology, Cornell University, 240 Uris Hall, Ithaca, NY 14853-7601, United States \\ ${ }^{\mathrm{b}}$ Department of Psychology, University of Washington, Guthrie Hall, Box 351525, Seattle, WA 98195-1525, United States
}

\section{Introduction}

Imagine a situation in which John comes across a man who asks him for help. Will John help? In The person and the situation: Perspectives of social psychology, Ross and Nisbett (1991) conclude that no information about John, such as how helpful he was in a different situation, will help predict whether he will offer the man assistance. Ross and Nisbett were not alone in their pessimistic account of personality. For decades, cross-situational inconsistency posed a puzzle and threatened the very idea of personality. How could one reconcile the intuition that people possess a coherent personality with empirical evidence of cross-situational invariability?

To account for both coherence of personality and cross-situational variability, Mischel and Shoda (1995) proposed the Cognitive-affective Processing System (CAPS) theory. To predict John's behavior, one needs to know about (i) the organization of his cognitive-affective processing system and (ii) the psychologically active features of situations that trigger particular processes within his network and lead to predictable behavior (Fig. 1A).

We propose that furthering knowledge of person by situation interactions requires refining our conceptualization and measurement of situations. We put forth our top four list to pursue this collective endeavor.

1. Identifying psychological features of situation. To the extent that John is affected by the presence of particular features in the situation (e.g., trustworthiness of the man asking for help), his behavior will covary with its magnitude. Highly-repeated measures designs (Shoda, 2003; Zayas, Whitsett, Lee, Wilson, \& Shoda, 2008) expose a participant to situations in which the presence of the feature varies and responses to each situation are tracked.

2. Not all features are the same: Units of analyses. One researcher may focus on how John's willingness to help is influenced by perceptions of the man's behaviors. However, another researcher may focus on the man's micro-facial expressions in the absence of behaviors. Just as different terms refer to particular types of cognitions and affects (expectancies, goals), developing a common language for situational units affords the possibility of linking units of situations to cognitive-affective

\footnotetext{
* Corresponding author. Fax: +1 6072558433.

E-mail address: vz29@cornell.edu (V. Zayas).
}

\section{Panel A.}

\section{John's "mind" as a}

network of cognitive-

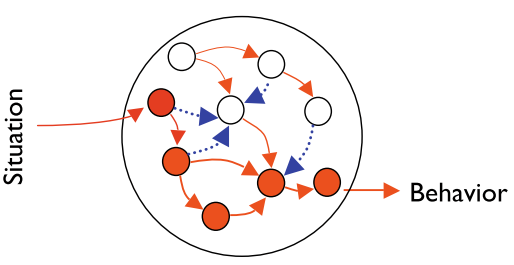

Panel B.

Tom

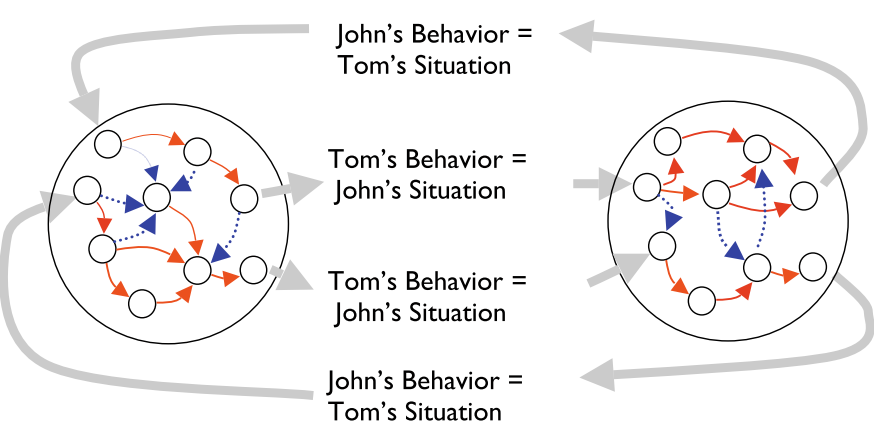

Fig. 1. (A) The large circle represents a person's mind conceptualized as a CognitiveAffective Processing System (CAPS) network. The network consists of a stable and unique network of cognitions and affects (represented by circles), which differs from that of another individual in the pattern and strengths of associations between concepts (represented by lines connecting the circles, and the absence of lines representing no association). The darkened circles represent thoughts and affects that are activated (accessible) as a result of features present in the current situation. This activation is assumed to propagate through the network of association and ultimately influences individual's experiences and behaviors. The undarkened circles represent those thoughts and affects that are not activated in the current situation. (B) The CAPS networks of two individuals may become "interlocked" so that the significant parts of the situations encountered by one partner consist of the behaviors of the partner, and vice-versa. For example, Tom and John are friends. The behavioral output from Tom's CAPS network becomes John's situation and it activates a particular cognitive-affective dynamic in John, leading to John's behavior. Similarly, the behavioral output from Mark's CAPS network becomes Tom's situation, which, in turn, activates in Tom a particular cognitive-affective dynamic, leading to his behavior.

processes and neural pathways. For example, the human face is processed automatically, effortlessly and quickly, whereas abstract, contextual cues may be processed more slowly. 
3. Integrating units. Even if John is motivated to provide help, the situation may simultaneously possess fear-eliciting features that could override the approach-help response. Ultimately, the meaning and impact of particular psychological features depends on other features present in the situation. Understanding the effects of situations means understanding how sets of cognitions and affects are activated and influence behaviors.

4. Significant aspects of situations. For John, the most significant aspect of his situation is the man asking for help. However, this situation has been randomly thrown upon him (by Ross \& Nisbett, 1991). In everyday life, individuals shape the situations they repeatedly encounter by choosing whom to interact with. These simple ideas (Zayas, Shoda, \& Ayduk, 2002) allow one to model significant parts of the situation by modeling the minds of interaction partners (Fig. 1B), such as repeated interactions between John and his longtime friend, Tom.

So, will John help the man sitting on the street corner? Perhaps it will be difficult to determine what John will do in this situation without knowing anything more about the man. But one may be able to predict how John will behave if the man asking for help is a his close friend, Tom, and we know what his request for help means to John.

\section{References}

Mischel, W., \& Shoda, Y. (1995). A cognitive-affective system theory of personality: Reconceptualizing situations, dispositions, dynamics, and invariance in personality structure. Psychological Review, 102, 246-268.

Ross, L., \& Nisbett, R. E. (1991). The person and the situation: Perspectives of social psychology. New York, NY: McGraw-Hill.

Shoda, Y. (2003). Studying persons in order to understand situations; studying situations in order to understand persons. In C. Sansone, C. Morf, \& A. Panter (Eds.), Handbook of methods in social psychology. Thousand Oaks, CA: Sage.

Zayas, V., Shoda, Y., \& Ayduk, O. N. (2002). Personality in context: An interpersonal systems perspective. Journal of Personality, 70, 851-898.

Zayas, V., Whitsett, D., Lee, J. J. Y., Wilson, N., \& Shoda, Y. (2008). From situation assessment to personality: Building a social-cognitive model of a person. In $\mathrm{G}$. Boyle, G. Matthews, \& D. Saklofske (Eds.). Handbook of personality theory and testing (Vol. 2, pp. 377-401). Thousand Oaks, CA: Sage. 